\title{
Excavation Method of Reducing Blasting Vibration in Complicated Geological Conditions
}

\author{
Lixiang Xie $\mathbb{D}^{\mathbb{D}},{ }^{1,2}$ Wenbo Lu $\left(\mathbb{D},{ }^{3}\right.$ Jincai Gu, ${ }^{1,2}$ and Gaohui Wang ${ }^{3}$ \\ ${ }^{1}$ State Key Laboratory for Geomechanics and Deep Underground Engineering, China University of Mining and Technology, \\ Xuzhou 221116, China \\ ${ }^{2}$ School of Mechanicals and Civil Engineering, China University of Mining and Technology, Xuzhou 221116, China \\ ${ }^{3}$ State Key Laboratory of Water Resources and Hydropower Engineering Science, Wuhan University, Wuhan 430072, China
}

Correspondence should be addressed to Lixiang Xie; xielixiang7688@126.com and Wenbo Lu; wblu@whu.edu.cn

Received 7 December 2017; Accepted 18 March 2018; Published 28 May 2018

Academic Editor: Francesco Pellicano

Copyright (C) 2018 Lixiang Xie et al. This is an open access article distributed under the Creative Commons Attribution License, which permits unrestricted use, distribution, and reproduction in any medium, provided the original work is properly cited.

Drilling and blasting method as a common excavation method is widely used in the underground engineering construction. However, in the complicated geological conditions, the path of blasting excavation available has limitation, and then the larger blasting vibration is produced, which influence the stability and safety of the protected structure. To effectively reduce the blasting vibration by optimizing the blasting excavation method, firstly, the site test on blasting vibration is conducted to obtain the blasting vibration data; secondly, the LS-DYNA software is applied to simulate the vibration generated by blasting in site test, based on back analysis on the blasting vibration, the mechanical parameters of the rock mass are obtained, and they are used to simulate six different types of blasting excavation method. According to the analysis on them, the reasonable blasting excavation method is proposed to reduce the blasting vibration which can satisfy the blasting safety regulation.

\section{Introduction}

In the process of blasting operation, the shock waves, stress waves, and earthquake waves subsequently develop. Due to the existence of these waves, the internal structure of the rock mass is inevitably influenced. When the vibration velocity exceeds a critical value, it can induce the formation of internal cracks in the rock mass, thus causing potential harm to the structure protected [1]. In some complicated geological conditions, the path of blasting excavation has limitation, and then the blasting source is close to some special protective structures which have strict requirements for blasting vibration. In such condition, to prevent the potential harm of internal crack formation resulting from the blasting vibration, the blasting excavation methods need to be optimized. Consequently, the optimized blasting method can be used to reduce blasting vibration in the complicated geological conditions, which provides reference for better application of the drilling and blasting method in the engineering construction.
To judge the potential damage of the blasting vibration to the structure of the rock mass, the reasonable blasting vibration safety criterion should be adopted according to the relationship between the inner structure failure of rock mass and vibration. The research shows that the inner structure failure of the rock mass is caused by the stress waves whose peak particle velocity (PPV) is related to the rock mass dynamic stress and dynamic strain [2-6]. Therefore, single PPV is widely used as the blasting vibration safety criterion in the early engineering practice [7]. However, it is found that when the blasting vibration amplitude is much higher than the control threshold, there is no damage to the protected object. While the blasting vibration amplitude is lower than the control threshold, the damage occurs. This is because there is no consideration of blasting earthquake wave frequency and natural frequency of the protected object. When their frequencies are equal, there is resonance phenomenon in structure, causing the failure of rock mass. Therefore, a relatively strict safety control criterion for blasting vibration has been developed, the bidirectional indicator of the PPV 
and blasting vibration frequency is used as blasting vibration safety criterion [6].

In order to study the influence of vibration caused by blasting excavation on rock mass structure, the methods of site test and numerical simulation are mainly used [8-12]. The site test can objectively reflect the influence of blasting vibration on the rock mass structure. However, due to the nonhomogeneity and the defects of the internal structure in the rock mass, the experimental conditions are difficult to control, so that less site tests are used to study the blasting vibration. Compared with the site tests, the numerical calculation can simulate the dynamic response problem in the complicated geological conditions, thus the numerical simulation method is widely used to analyze the blasting vibration response.

At present, lots of commercial software are used in the numerical simulation of blasting vibration such as LS-DYNA, AUTODYN, UDEC/3DEC, ABAQUS, and FLAC [1]. Zhao et al. applied UDEC software to study the attenuation law of stress wave through the joint fissure [13]. Vorobiev [14, 15] used AUTODYN to study the propagation law of the stress waves passing the joint medium using the equivalent and direct simulation method and found the strong ability of AUTODYN to simulate the blasting vibration. Onederra et al. [16] and Resende et al. [17] used FLAC3D dynamic analysis module to analyze the surface response caused by blasting vibration, and compared with the measured data, the calculation results show that FLAC3D was feasible for numerical simulation of dynamic response under blasting load. Chen et al. [18] used LS-DYNA software to study the blasting vibration safety control criteria for underground plant blasting.

When the numerical simulation software is used to study the impact of explosive explosion on the rock mass structure, the correct explosive model and the loading method of the explosion load are the key to simulate the vibration response of rock mass. According to the detonation reaction type after explosive explosion, it is clarified into ideal detonation and nonideal detonation [19-21], so that the shape of explosive load induced in rock mass is not the same. In the numerical simulation software, the explosive explosion is regarded as the ideal detonation type, and the corresponding equation of state (EOS) is used to simulate the effect of the explosive explosion on the rock mass. In the software like LS-DYNA [22-24], AUTODYN [25, 26], ABAQUS [27], and JonesWilkins-Lee (JWL) $[28,29]$, EOS is commonly used in the numerical simulation of large-scale blasting engineering. However, in the process of numerical simulation, the large deformation and distortion of the finite elements at high pressure often cause the calculation process to be terminated when using JWL EOS. In order to overcome this problem, fluid-solid coupling method and the method of applying pressure delay function are usually used [30-36]. The fluidsolid coupling method needs to refine the element grid of rock mass near the boreholes, since more unit grids are required in the numerical calculation of large-scale blasting engineering, which raises the numerical calculation difficulty. Compared with the fluid-solid coupling method, the method of applying pressure delay attenuation function can reduce the number of element grids and is widely used in numerical simulation of large-scale blasting engineering.
To effectively reduce the blasting vibration by optimizing the blasting excavation method, firstly, the site test on blasting vibration is conducted to obtain the blasting vibration data. Secondly, the LS-DYNA software is applied to simulate the vibration generated by blasting in site test. The mechanical parameters of the rock mass are acquired by back analysis on the blasting vibration, and they are used to simulate six different types of blasting excavation method. According to the analysis on them, the reasonable blasting excavation method is proposed to reduce the blasting vibration.

\section{Engineering Background}

Fengning pumped storage power station is a first-class largescale Water Conservancy and Hydropower Engineering. Its construction is divided into two phases that the excavation in the phase I engineering construction has been completed, and the phase II engineering construction is in feasibility study phase. According to the geological exploration results, there are many faults near the underground powerhouse in the phase II as shown in Figure 1. Due to such restriction of complicated geological conditions and limited watercourse system layout, combined arrangement scheme in phase II engineering construction has to be chosen, and their axial directions are consistent. Since the excavation in the phase I engineering construction has been completed, the internal structure in the phase I engineering construction will inevitably be influenced by blasting vibration in the phase II engineering construction. In such condition, on account of the strict control requirement for blasting vibration, reasonable selection for blasting excavation method should be conducted, so as to ensure the safety of the internal structure in the phase I project along with the orderly construction of the entire project. It can be seen that it is of great significance to study the optimized blasting excavation method regarding this engineering as research background, which can provide reference for the application of drilling and blasting method in engineering construction.

\section{Back Analysis on Rock Mass Blasting Parameters}

3.1. Site Experiment. When the Fengning phase II engineering construction is conducted, taking the opportunity of excavating survey tunnel in underground powerhouse, the cutting holes are dilled to carry out the cut blasting tests in the appropriate position of the survey tunnel, and the design scheme of cutting blasting experiment is shown in Figure 2. The vibration data in the cutting blasting test and the given mechanical parameters of the rock mass are used to conduct back analysis on the mechanical parameters of the rock mass in numerical calculation.

3.2. Model for Parameter Inversion. The model has been established using the dynamic finite element software of Ansys/Ls-dyna as shown in Figure 3. The numerical model has a length of $118.5 \mathrm{~m}$, a width of $90 \mathrm{~m}$ and a height of $105 \mathrm{~m}$, nonreflection boundary is set on the surroundings 


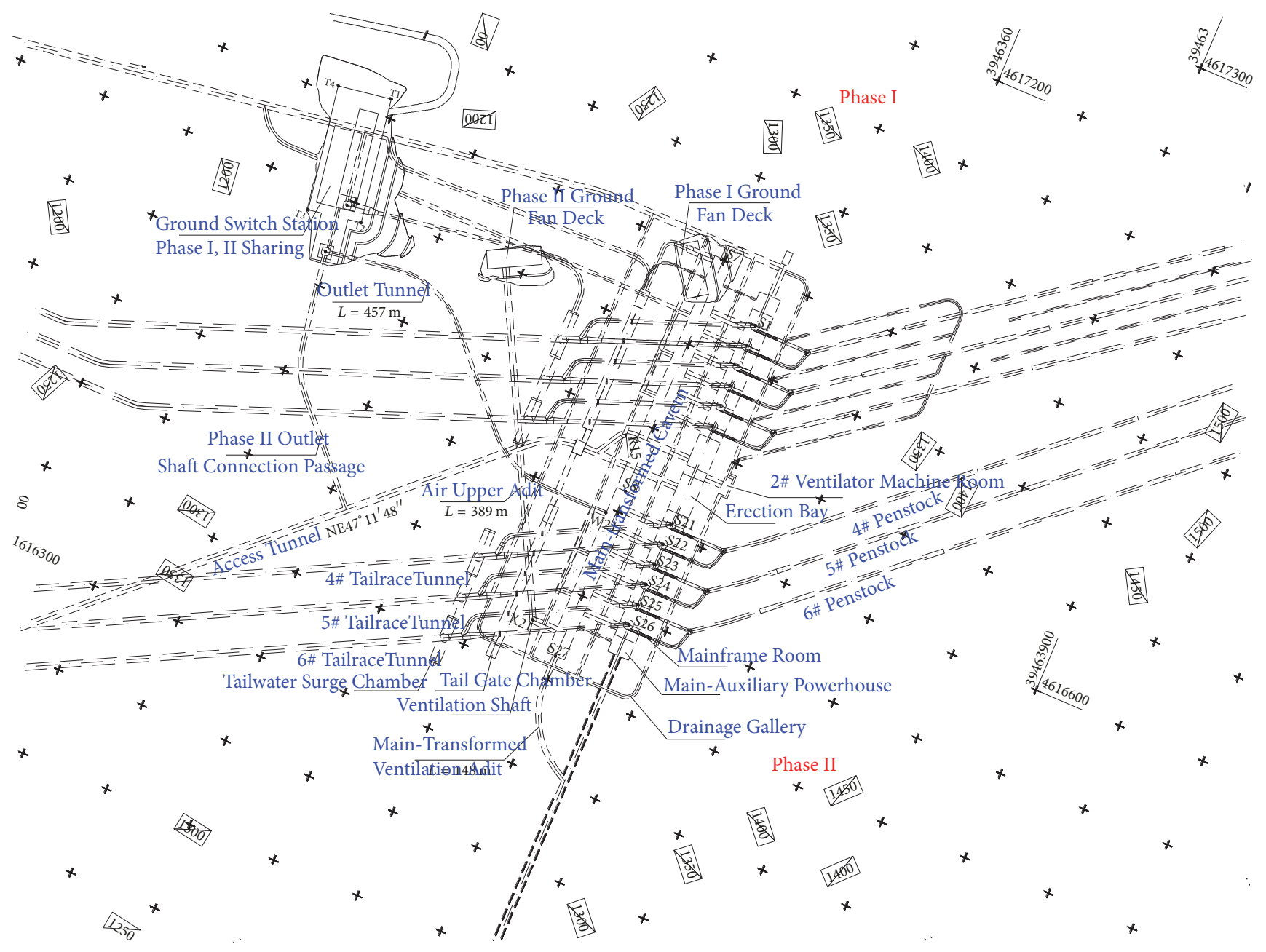

FIGURE 1: Layout plan for underground powerhouses of two phases of construction.

of the model, and full constraint condition is set on the bottom surface. The number of elements and nodes for the numerical calculation model are 376480 and 392906, respectively. Considering the effect of excavated rock masses on retaining rock masses, the periphery of survey tunnel in the range of $1.5 \mathrm{~m}$ was weakened, which is reflected in the elastic modulus reduction of rock mass.

3.3. Selection of Rock Mass Mechanics Inversion Parameters. Under the action of fierce explosion load, a complex process takes place near the blasting source, including the propagation of compressive stress waves, plastic deformation, and the medium failure and the formation of explosion cavity. Consequently, the rock around the borehole is divided into crushed zone, fractured zone, and elastic vibration zone according to the fractured degree. In order to adopt the elastic constitutive relationship based on continuum mechanics, the nonelastic zone (crushing zone and fractured zone) is equivalent to the blasting source, and the explosion load is applied to the equivalent elastic boundary. In this blasting experiment, the borehole diameter is $42 \mathrm{~mm}$; charge diameter is $32 \mathrm{~mm} ; 2$ \# rock emulsion explosive is used, and its parameters are as follows: density is $1243 \mathrm{~kg} / \mathrm{m}^{3}$, detonation velocity is $3600 \mathrm{~m} / \mathrm{s}$, and $\gamma$ is 1.4 . In calculation, crushing zone takes 3 times the charge diameter, elastic boundary takes 8 times the charge diameter, and the equivalent load on borehole is $44.3 \mathrm{MPa}$. And the calculation methods of the equivalent load are shown in Appendix.

In order to study the impact of blasting vibration on the structure of rock masses, the explosion load is generally equivalent to a triangular load, and it is applied to the borehole wall or equivalent elastic boundary. Kuzmenko et al. [37] have given the time domain expression of triangular explosion load, and its time domain expression is as follows:

$$
\sigma(t)= \begin{cases}0 & t<-t_{u} \\ \sigma_{\max }\left(1+\frac{t}{t_{u}}\right) & -t_{u} \leq t<0 \\ \sigma_{\max }\left(1-\frac{t}{t_{d}}\right) & 0<t \leq t_{d} \\ 0 & t>t_{d},\end{cases}
$$

where $\sigma_{\max }$ is the peak of the triangular load; $t_{u}$ and $t_{d}$ are the rising time and falling time of triangular load, respectively. 


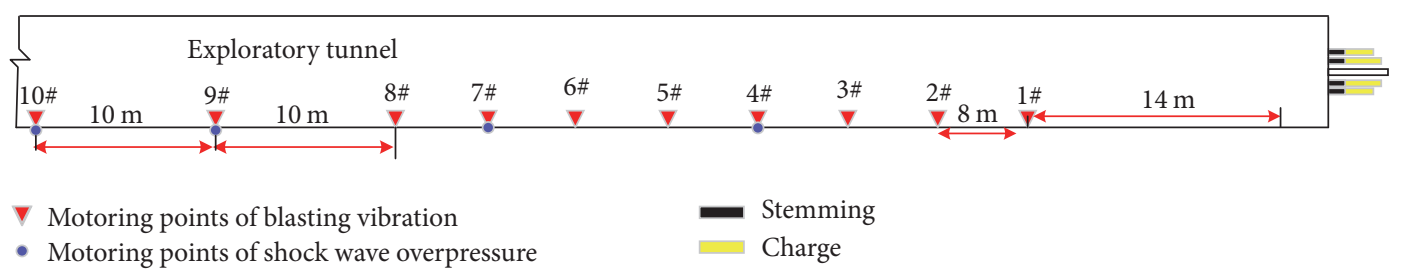

(a)

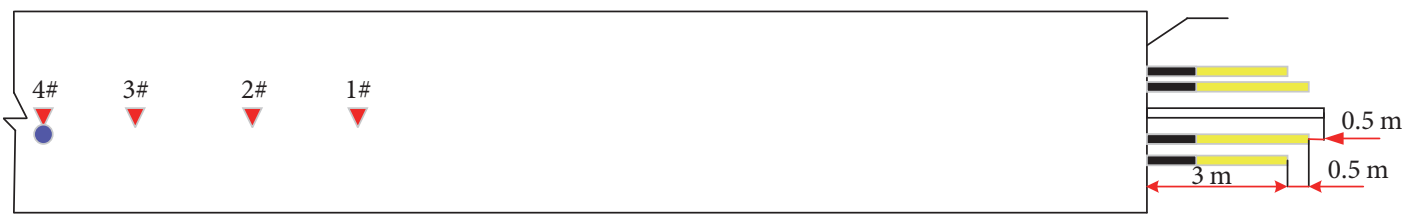

$\checkmark$ Motoring points of blasting vibration

- Motoring points of shock wave overpressure

Stemming

Charge

(b)

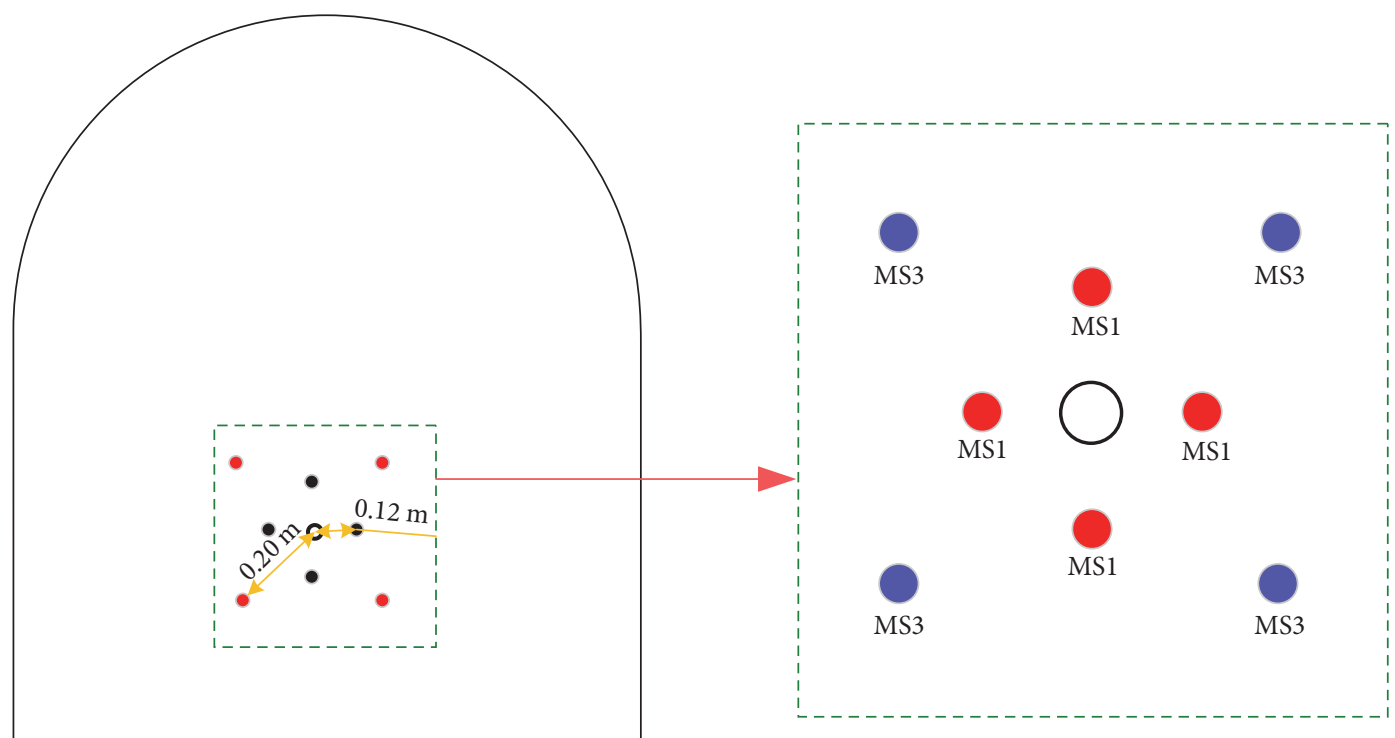

- First circle cut hole

- Second circle cut hole

- Empty hole

(c)

FIGURE 2: Design sketch of blasting experiment: (a) distribution of monitoring points in longitudinal direction, (b) distribution of monitoring points in horizontal direction, and (c) cut holes arrangement in the position of tunnel surface.

It is generally considered that the rising time of explosion load is equal to the propagation time of detonation wave in the borehole. For the hole-bottom initiation, it meets the following formula:

$$
t_{u}=\frac{L_{1}}{D},
$$

where $L_{1}$ is the charge length of the borehole; $D$ is the detonation velocity of explosive explosion.

At present, many scholars have different opinions about the duration of explosion load. Considering the processes of explosive initiation, cracks connection between boreholes, and escaping of detonation gas, Lu et al. [38] proposed a new method to calculate the duration of the explosion load based on explosion mechanics, fracture mechanics, fluid mechanics, and other basic theories. It can be used to simulate the vibration response of rock mass in the middle and far zone from explosion source. The duration of explosion load is expressed as follows:

$$
\begin{aligned}
& t_{s}=\frac{L_{1}}{D}+\frac{\sqrt{(1 / 4) L_{s}{ }^{2}+L_{2}{ }^{2}}}{c_{f}} \\
& +\max \left(\frac{L_{1}+L_{2}}{v_{a}}, \frac{L_{1}+L_{2}}{c_{a}}\right)+\frac{L_{1}+L_{2}}{c_{b}},
\end{aligned}
$$




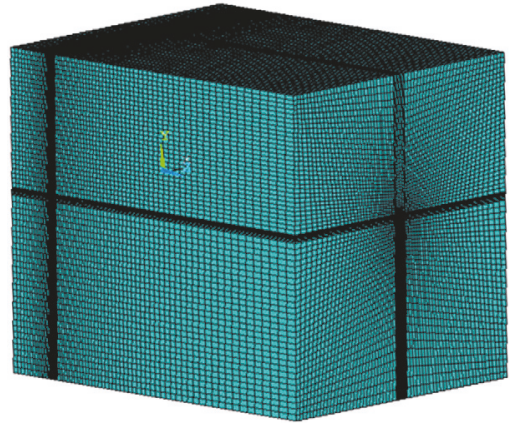

(a)

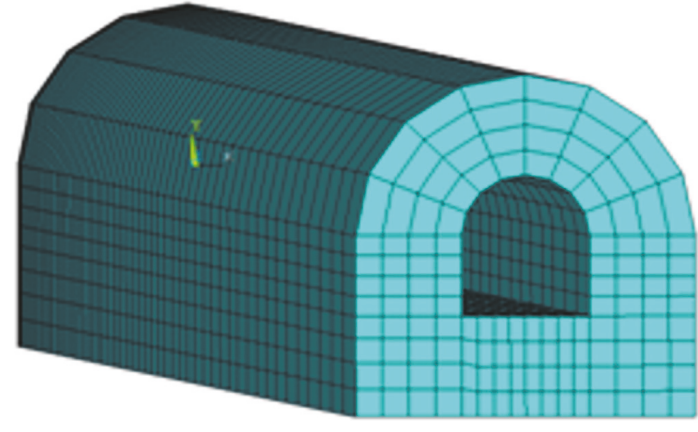

(b)

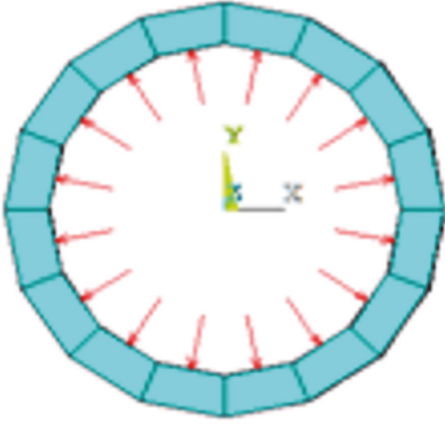

(c)

Figure 3: Numerical inversion model: (a) numerical model, (b) weakened rock masses in numerical model, and (c) applied equivalent load on wall of borehole.

where $t_{s}$ is the duration of explosion load; $L_{s}$ is the distance between adjacent blasthole; $L_{2}$ is the stemming length of the blasthole; $c_{f}$ is the average velocity of crack propagation driven by explosion load; $c_{a}$ is the unloading wave velocity of the explosion gas; $c_{b}$ is the velocity of the reflected unloading wave propagating from bottom of the boreholes to the orifice; $v_{a}$ is the escaping velocity of explosion gas.

Using (2) and (3) to calculate the rising time and falling time of the equivalent triangular blasting load in (1), it is as shown in Figure 4.

\subsection{Selection of the Rock Mass Mechanical Parameters.} Numerical calculation and parameter inversion are carried out by applying triangular load as shown in Figure 4. Table 1 shows the comparison of PPV between measured and numerical simulation results for the $7 \#$ measured point. Figure 5 is the waveform comparison between the measured and numerical simulation results. From Figure 5 and Table 1, it can be seen that there is a good consistency in the PPV, main frequency, and duration of blasting vibration. Then the inversion mechanical parameter value of rock mass is shown in Table 2 .

\section{Numerical Model}

4.1. Numerical Model Establishment. According to phase I and phase II underground powerhouse layout in Fengning Pumped Storage Power Station drawings, the threedimensional CAD Model is established and importing it into the finite element software for CAE analysis. The threedimensional finite element model is shown in Figure 6, and the number of elements and nodes in the numerical calculation model are 996525 and 1026030, respectively. Distance between the excavation boundary and the model boundary is $53 \mathrm{~m}$. To eliminate the influence of reflected stress wave, nonreflection boundary is set on the surroundings of the model, and full constraint condition is set on the bottom surface. The influence of in situ stress is not considered due to smaller buried depth.

4.2. Design Scheme. In order to select the appropriate blasting excavation method to reduce the blasting vibration

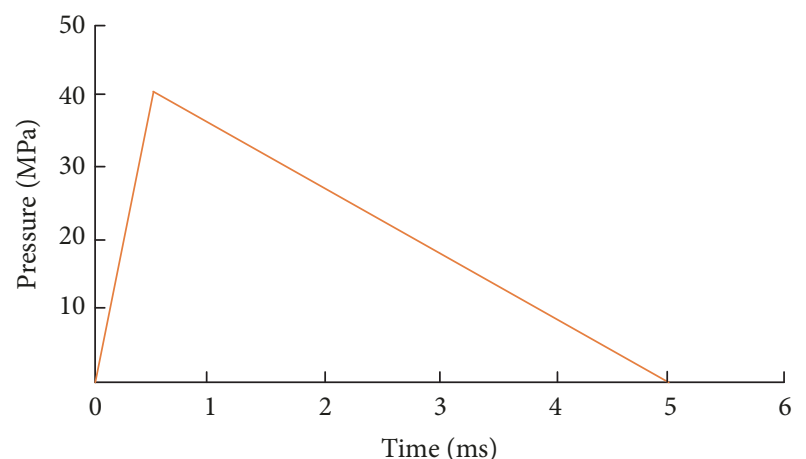

FIGURE 4: Numerical simulation inversion of the equivalent triangular load.

in complicated geological conditions, numerical simulation comparison is conducted for six different kinds of blasting excavation scheme, the design scheme of blasting excavation: (a) draw cut blasting of deep hole; (b) draw cut blasting of shallow hole; (c) presplitting blasting of deep hole; (d) presplitting blasting of shallow hole; (e) draw cut blasting with presplitting gap; (f) draw cut blasting with damping ditch. Six kinds of design scheme are shown in Figure 7.

4.3. Loading Conditions. According to the formula in Appendix, the pressure peak acting on borehole wall for draw cut blasting is $19.0 \mathrm{MPa}$, the rising time of the loading section is $2.0 \mathrm{~ms}$, and the duration is $8.0 \mathrm{~ms}$. The equivalent load of deep and shallow hole presplit blasting can be taken as 7.0 and $9.35 \mathrm{MPa}$, respectively. Their rising time of the loading sections is 1.2 and $0.67 \mathrm{~ms}$, respectively, and their durations are 7.2 and $6.67 \mathrm{~ms}$, respectively.

4.4. Layout of Measuring Points. In order to accurately analyze the vibration response of phase I underground powerhouse and erection bay, the monitoring points are set in key parts such as the generator sets, turbine layers, and erection bay. By monitoring the velocity distribution of the measuring points in different positions, the influence of blasting excavation in the phase II underground powerhouse on phase 
TABLE 1: The comparison of vibration peak between the measured and numerical simulation results in Fengning site test.

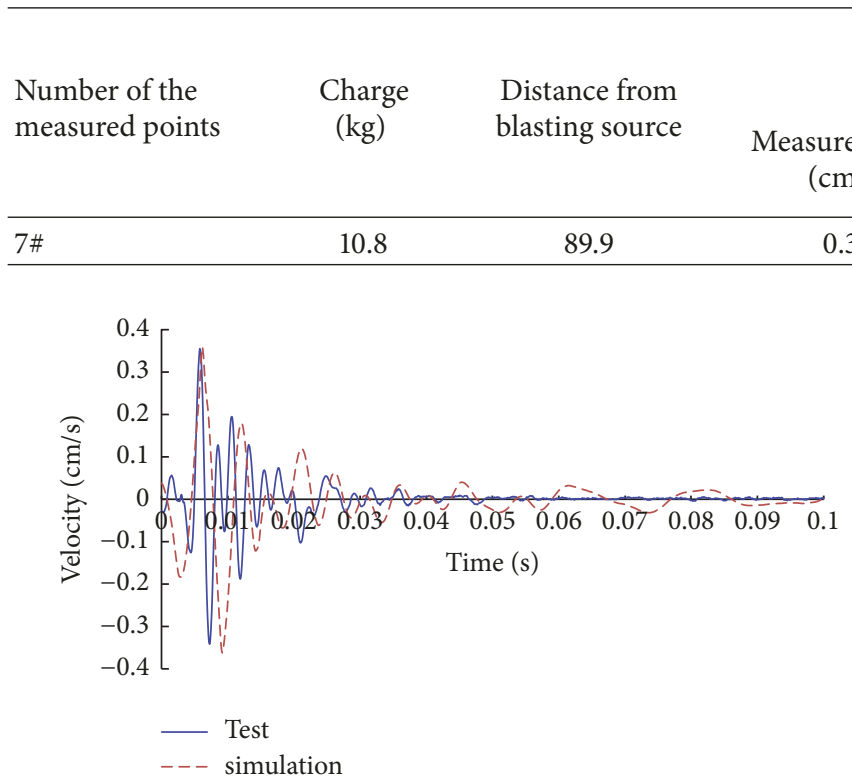

(a)

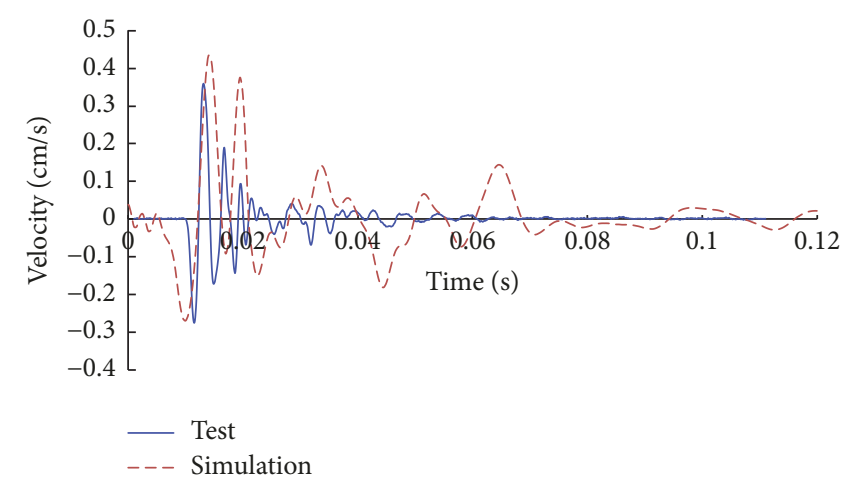

(b)

FIGURE 5: The comparison of the vibration velocity of the 7 \# measured point between the numerical calculated value and measured value: (a) vertical direction and (b) horizontal direction.

TABLE 2: The results of rock mass parameters inversion.

\begin{tabular}{lccc}
\hline Rock category & $\begin{array}{c}\text { Elastic modulus } \\
(\mathrm{GPa})\end{array}$ & Poisson's ratio & $\begin{array}{c}\text { Density } \\
\left(\mathrm{kg} / \mathrm{m}^{3}\right)\end{array}$ \\
\hline Fresh rock & 24 & 0.24 & 2610 \\
Weaken rock & 20 & 0.25 & 2500 \\
\hline
\end{tabular}

I underground powerhouse can be comprehensively and accurately evaluated. To save numerical calculation amount, there are three sets, $4 \#, 5 \#$, and $6 \#$, to be analyzed because they are close to the blasting source. To monitor the vibration response law, six monitoring points are set in the three generator sets as shown in Figure 8, number 1, number 2, and number 3 in the three generator layer sets and number 4 , number 5 , and number 6 in the three turbine layers, respectively. When blasting excavation is conducted in the phase II underground powerhouse, the phase I underground powerhouse is in the period of concrete pouring. According to the blasting safety regulations, the relatively small PPV is required. As the concrete in the phase I underground powerhouse is being poured, to further understand whether the blasting vibration caused by the blasting excavation in the phase II underground powerhouse meets the requirements of the blasting safety regulations, the monitoring points, number 8 , number 9 , and number 10, are set in the 6\# set as shown in Figure 8.

\section{Results and Discussion}

The vibration response of each key control protected object is shown in Tables 3 and 4 and Figures 9 and 10. The results show that different blasting excavation methods have a great influence on the vibration response in the phase I underground powerhouse.

When draw cut blasting methods of deep and shallow hole in phase II underground powerhouse are adopted, respectively, the PPV of the critical control points in the generator layer are 0.92 and $0.44 \mathrm{~cm} / \mathrm{s}$ (along axial direction of borehole), respectively. The PPV of the critical control points meets the requirements of vibration safety control standards in Table 5. The vibration effect of blasting excavation on the phase I underground powerhouse can be effectively reduced by using the draw cut blasting method of shallow hole.

In the draw cut blasting of deep hole, the PPV in the three monitoring points of $6 \#$ set, number 8 , number 9 , and number 10 , are $1.43,1.98$, and $2.57 \mathrm{~cm} / \mathrm{s}$, respectively, as shown in Figure 11. As to the draw cut blasting of shallow hole, their $\mathrm{PPV}$ is $0.81,1.08$, and $1.71 \mathrm{~cm} / \mathrm{s}$, respectively. This proves that there is a certain amplification effect for blasting vibration velocity along the height of the set. When the excavation of phase II underground powerhouse is being carried out, the phase I underground powerhouse is in the period of concrete pouring, and the PPV exceeds the $1.5 \mathrm{~cm} / \mathrm{s}$ of the safety control standard for the $0 \sim 3 \mathrm{~d}$ aged initial coagulation concrete. However, it meets $3.0 \mathrm{~cm} / \mathrm{s}$ of the safety control standard for $3 \sim 7 \mathrm{~d}$ aged concrete. Therefore, to satisfy the safety control standard, when the concrete is being poured in the phase I underground powerhouse, the vibration effect of blasting excavation can be controlled by increasing its age or reducing the amount of charge.

When the phase II underground powerhouse is being excavated, to develop a certain width cracks in the position of predesigned contours, the presplit blasting is performed to buffer and reflect the blasting vibration waves, consequently, 
TABLE 3: Maximum PPV of each key control protected object using 6 types of blasting excavation method in I phase underground powerhouse.

\begin{tabular}{|c|c|c|c|c|}
\hline Scheme & Charge (kg) & $\begin{array}{c}\text { Generator layer } \\
(\mathrm{cm} / \mathrm{s})\end{array}$ & $\begin{array}{l}\text { Turbine layers } \\
(\mathrm{cm} / \mathrm{s})\end{array}$ & $\begin{array}{c}\text { New pouring concrete } \\
(\mathrm{cm} / \mathrm{s})\end{array}$ \\
\hline Draw cut of deep hole & 24.0 & 0.92 & 0.68 & 2.57 \\
\hline Draw cut of shallow hole & 10.8 & 0.44 & 0.43 & 1.71 \\
\hline Presplitting blasting of deep hole & 12.0 & 0.22 & 0.18 & 0.75 \\
\hline $\begin{array}{l}\text { Presplitting blasting of shallow } \\
\text { hole }\end{array}$ & 7.3 & 0.16 & 0.13 & 0.60 \\
\hline $\begin{array}{l}\text { Draw cut blasting with } \\
\text { presplitting gap }\end{array}$ & 24.0 & 0.89 & 0.63 & 2.43 \\
\hline Draw cut with damping ditch & 24.0 & 0.31 & 0.21 & 0.83 \\
\hline
\end{tabular}

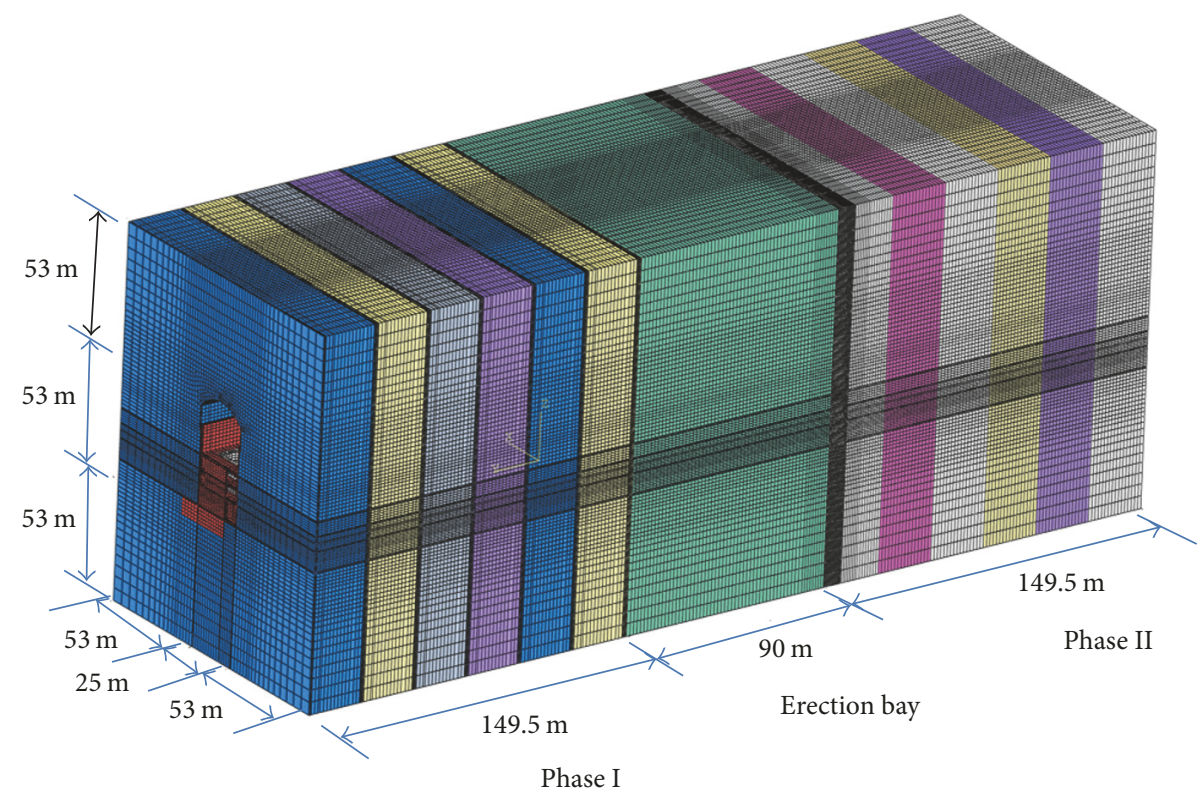

(a)

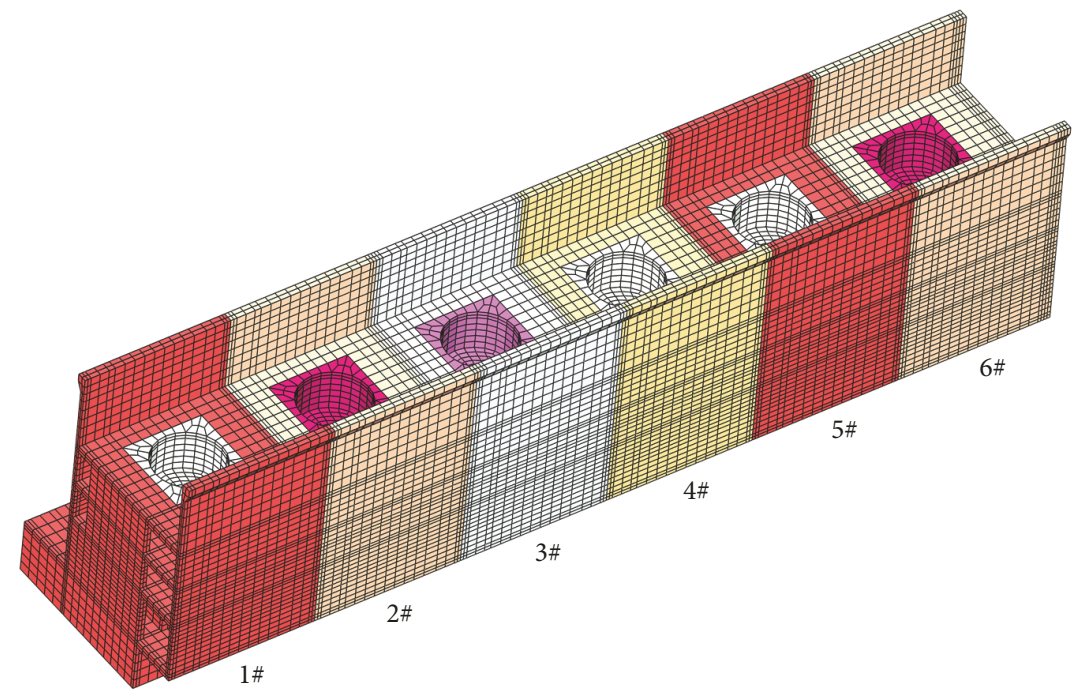

(b)

FIGURE 6: Phase I and II underground plant model: (a) overall three-dimensional model of CAE for phase I and II underground powerhouse and (b) three-dimensional model of CAE for phase I underground powerhouse. 


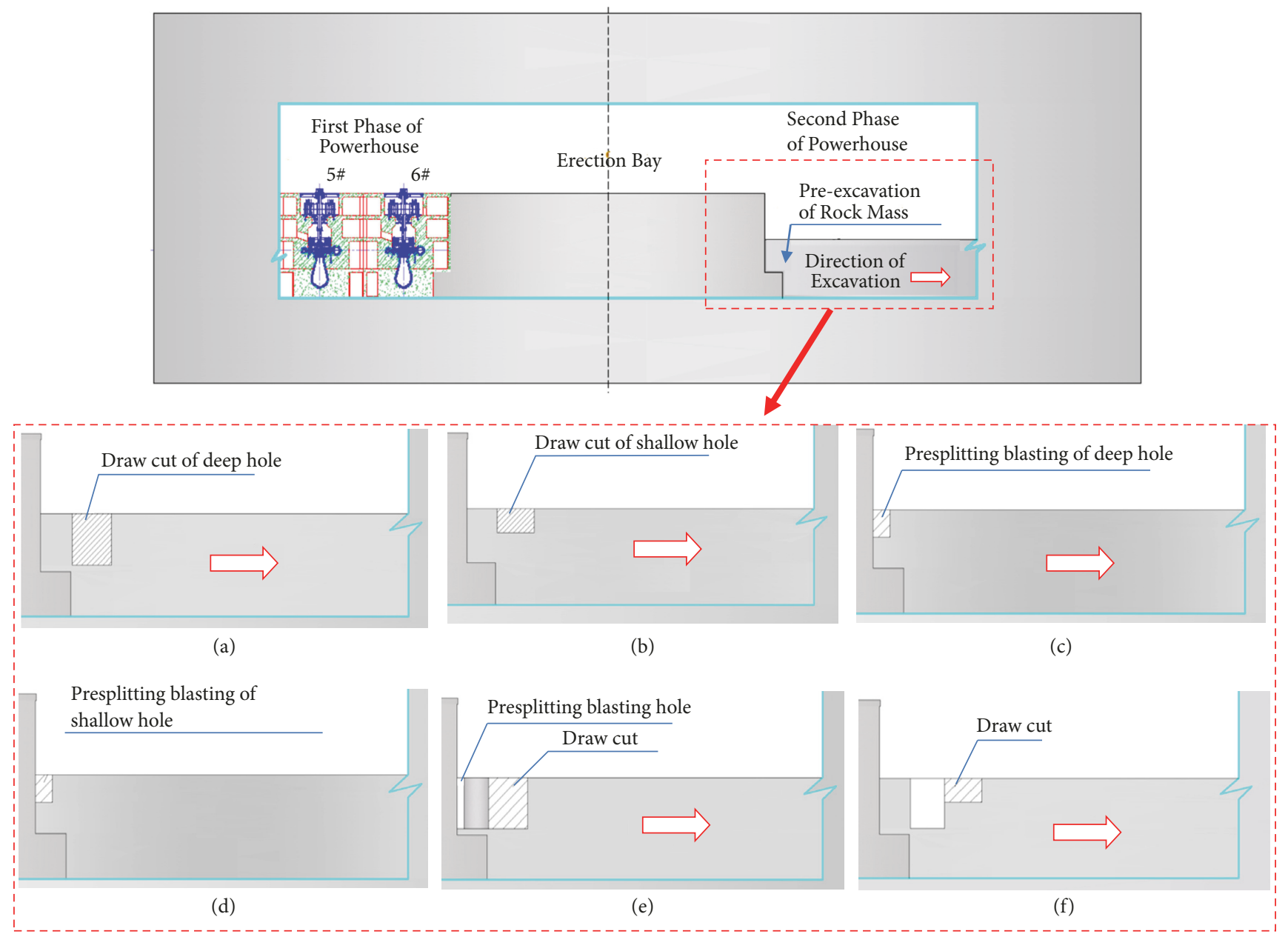

FIGURE 7: Six kinds of blasting excavation methods.
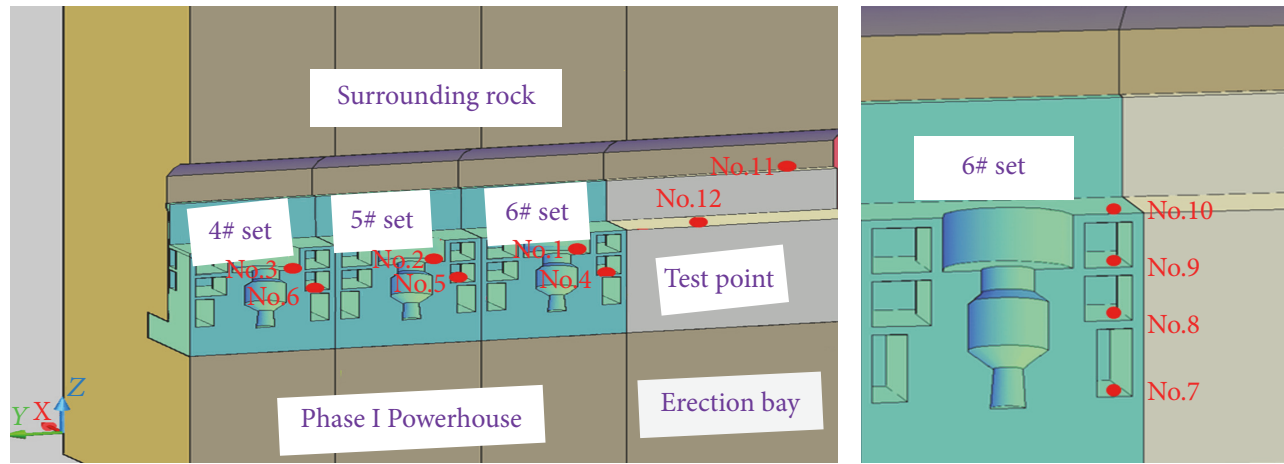

FIGURE 8: Monitoring points of simulation.

the damage to the retaining rock mass can be effectively controlled. The maximum vibration velocity of the phase I underground powerhouse is $0.22 \mathrm{~cm} / \mathrm{s}$ in the presplitting blasting of deep hole. As to presplitting blasting of shallow hole, its maximum vibration velocity is $0.16 \mathrm{~cm} / \mathrm{s}$, and all of them are located at $6 \#$ set. Therefore, the presplitting blasting of shallow hole can be applied to effectively reduce the vibration velocity induced in the phase I underground powerhouse.

According to the analysis of vibration response on the draw cut blasting of deep hole with presplitting gap, the maximum vibration velocity of the generator layer is $0.89 \mathrm{~cm} / \mathrm{s}$ (along axial direction of borehole). Compared with the direct draw cut blasting of deep hole, the maximum 


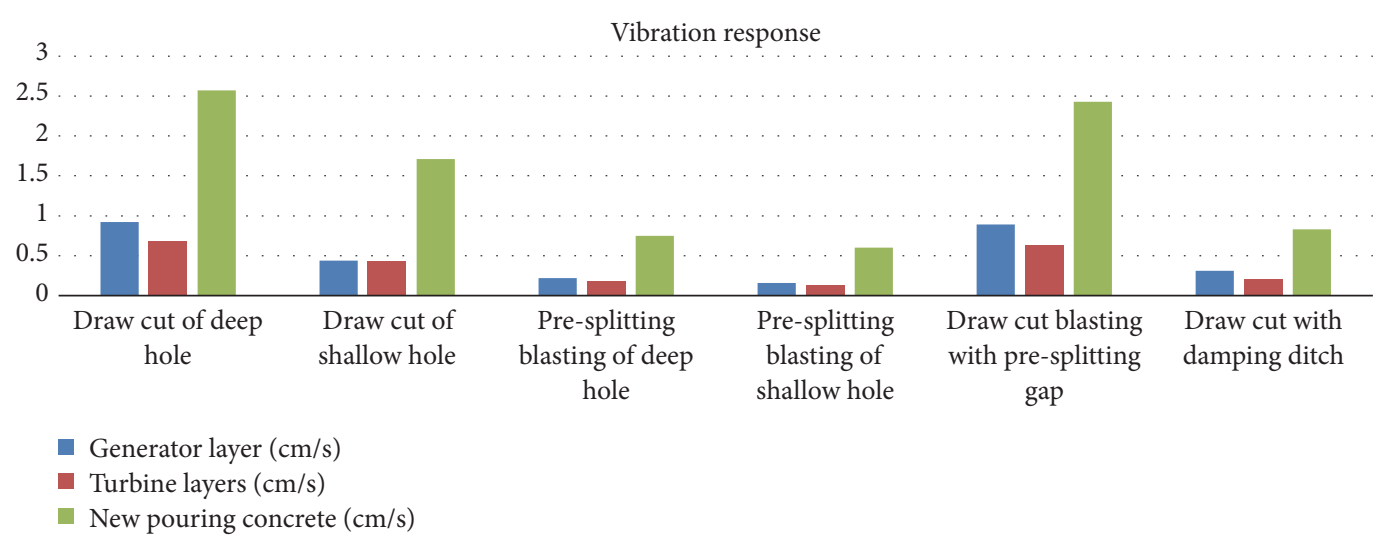

FIGURE 9: Comparison of vibration response for different blasting excavation methods in the critical control points.
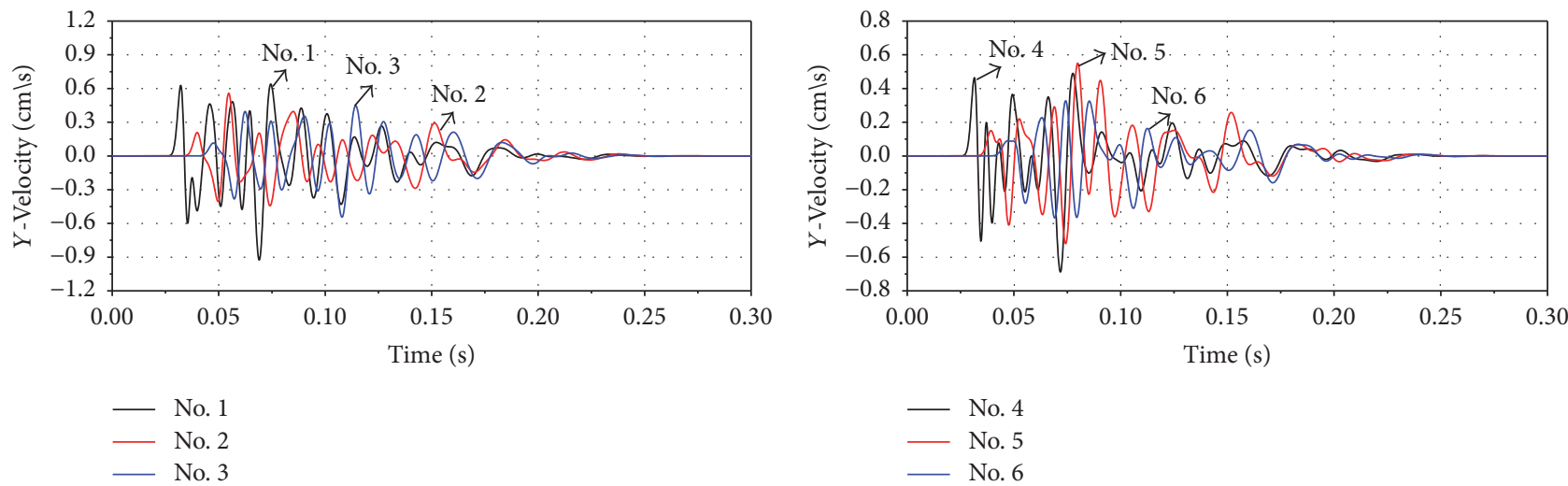

(a)

(b)
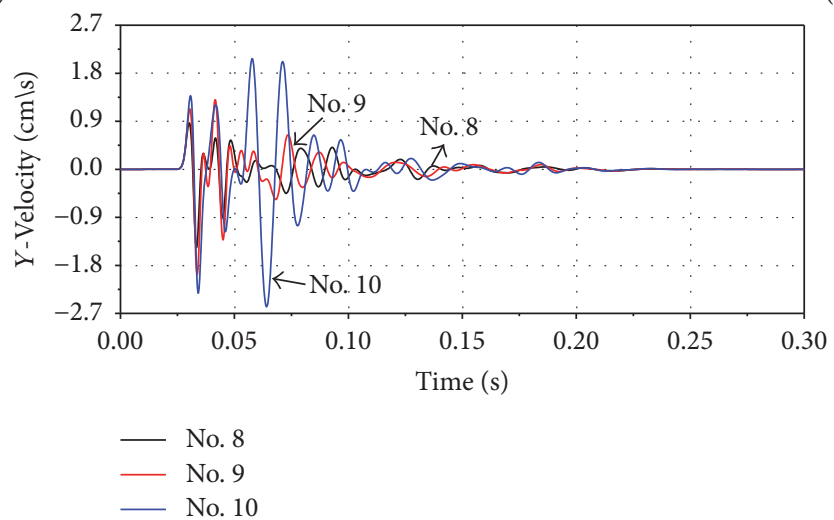

Figure 10: Axial velocity in draw cut blasting of deep hole: (a) axial velocity of generator layer in draw cut blasting of deep hole; (b) axial velocity of turbine layers in draw cut blasting of deep hole; (c) axial velocity of different elevation for 6\# generator sets in draw cut blasting of deep hole.

TABLE 4: Axial peak velocity of different elevation for 6\# generator sets in draw cut blasting of deep hole.

\begin{tabular}{lccc}
\hline Monitoring points & Number 8 & Number 9 & Number 10 \\
\hline Elevation & 970.5 & 976.5 & 982.5 \\
Axial velocity $(\mathrm{cm} / \mathrm{s})$ & 1.43 & 1.98 & 2.57 \\
\hline
\end{tabular}

vibration velocity is relatively smaller. In the three monitoring points of $6 \#$ set, number 8 , number 9 , and number 10 , their
PPV are $1.08,1.49$, and $2.43 \mathrm{~cm} / \mathrm{s}$, respectively. When the phase I underground powerhouse is being excavated and concrete poured, part of the vibration response does not meet the safety control standard, and the concrete age can be controlled to satisfy the safety control standard.

According to the analysis of the vibration response characteristics on draw cut blasting with damping ditch, it shows that the vibration response of the phase I underground powerhouse is smaller, the maximum vibration velocity of the generator layer is $0.31 \mathrm{~cm} / \mathrm{s}$, and the maximum vibration 


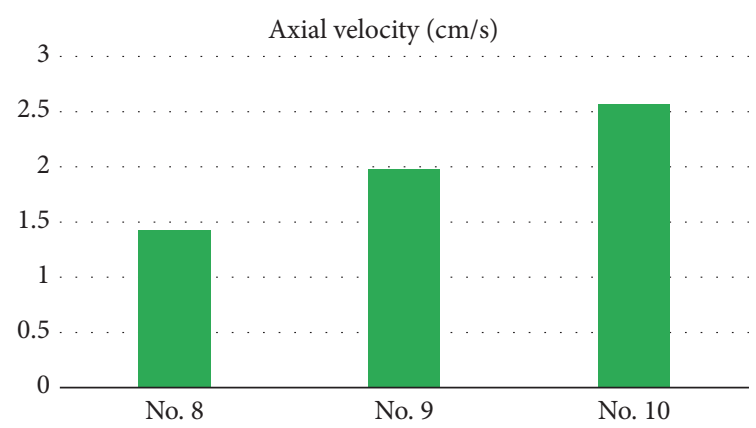

FIGURE 11: Amplification effect for blasting vibration in 6\# set.

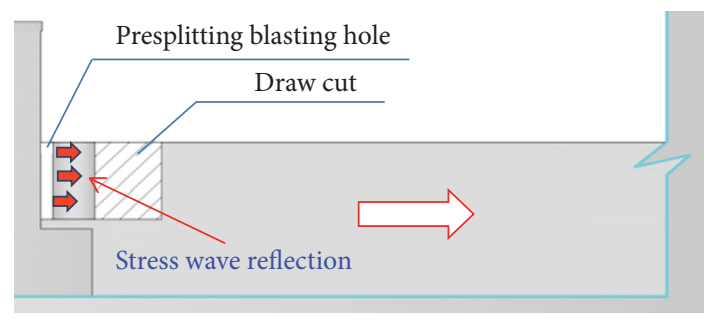

(a)

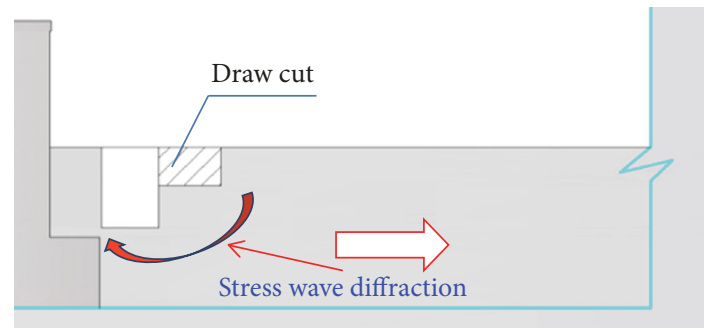

(b)

FIGURE 12: Mechanism of reducing blasting vibration: (a) presplitting blasting before draw cut blasting; (b) draw cut with damping ditch.

TABLE 5: Safety control standard of blasting vibration in Fengning pumped storage power station.

\begin{tabular}{lcc}
\hline Protected projects & Minimum distance $(\mathrm{m})$ & Standard $(\mathrm{cm} / \mathrm{s})$ \\
\hline Generator layer & 60 & $\leq 2.5$ \\
Turbine layers & 60 & $\leq 2.5$ \\
New pouring concrete & & \\
0 3d & 54 & $\leq 1.5$ \\
3 7 d & 54 & $\leq 3.0$ \\
7 28 d & 54 & $\leq 7.0$ \\
\hline
\end{tabular}

velocity of fresh concrete is $0.83 \mathrm{~cm} / \mathrm{s}$. In the combination of phase I underground powerhouse progress construction period and phase II underground powerhouse construction progress, the vibration velocity of the phase I underground powerhouse meets the requirements for the safety control standard when there is damping ditch.

Based on above analysis, the blasting vibration can be reduced by draw cut blasting with presplitting gap and draw cut with damping ditch. Their mechanism of reducing blasting vibration can be shown in Figure 12. When presplitting blasting is performed before draw cut blasting, a certain width crack in the position of predesigned contours is produced to buffer and reflect the blasting vibration waves, which reduces the incident wave intensity; consequently, the blasting vibration can be effectively controlled. As for draw cut with damping ditch, due to damping ditch, stress wave diffraction changes the propagation path of stress waves, and then increasing the stress wave propagation distance, consequently, the energy is dissipated in the stress wave propagation; accordingly, the blasting vibration is effectively reduced in the critical control points.

\section{Conclusion}

The influence of different blasting excavation methods in phase II underground powerhouse on the phase I underground powerhouse is analyzed and simulated by threedimensional dynamic finite element method. According to analysis on the vibration response of each key control protected object, the effective methods to reduce blasting vibration are achieved as follows:

(1) Apart from the new pouring concrete, the PPV of the structures and equipment completed in the phase I underground powerhouse meets the vibration peak safety control standards.

(2) The application of draw cut blasting of shallow hole and draw cut blasting with damping ditch can effectively reduce the influence of the blasting vibration on the phase I underground powerhouse.

(3) When pouring concrete is being conducted in the phase I underground powerhouse, it can satisfy the safety vibration control standards by controlling the age of the pouring concrete.

\section{Appendix}

For the blasting load, according to the C-J theory of detonation wave for condensed explosives, the initial average detonation pressure acting on the borehole wall in the condition of coupled charge is as follows:

$$
P_{0}=\frac{\rho_{0} D^{2}}{2(\gamma+1)},
$$

where $P_{0}$ is the detonation pressure of explosive; $\rho_{0}$ and $D$ are the density and detonation speed of explosive, respectively; $\gamma$ is the isentropic exponent.

For the uncoupled charge, if the coupled coefficient $b / a$ is small ( $a$ is the diameter of charge), the expansion of the explosion gas is only one state of $P>P_{k}$, and the initial average pressure of the borehole is

$$
P_{0}=K \frac{\rho_{0} D^{2}}{2(\gamma+1)}\left(\frac{a}{b}\right)^{2 \gamma},
$$

where $a$ is the diameter of charge; $b$ is the diameter of borehole; $\alpha$ is the ratio of axial charge; $K$ is the pressure increasing 
coefficient when the detonation product colliding with the borehole wall; $S$ is the distance between adjacent holes.

If the uncoupled coefficient of the charge is large, the expansion of explosion gas can be divided into two phases, that is, $P \geq P_{k}$ and $P<P_{k}$. The isentropic exponent $\gamma$ is 3.0, and (A.2) is used for calculation in the condition of $P \geq P_{k}$; the isentropic exponent $\gamma$ is 1.4 , and (A.3) is used for calculation in the condition of $P<P_{k}$.

$$
P_{0}=K\left(\frac{\rho D^{2}}{2(\gamma+1)}\right)^{\nu / \gamma} P_{k}^{(\gamma-\gamma) / \gamma}\left(\frac{a}{b}\right)^{2 \nu} .
$$

The explosion gas pressure acting on the borehole wall will be attenuated in the form of the exponential law when the stress waves propagate in the rock mass. Then its exponential attenuation formula is used. Considering the initiation influence of group boreholes, the influence coefficient of the group borehole initiation is assumed to be $k$, and the blasting load equivalent to the elastic boundary can be expressed as

$$
P_{\mathrm{be}}=k P_{0}\left(\frac{b}{r_{c}}\right)^{2+(\mu /(1-\mu))}\left(\frac{r_{c}}{r_{f}}\right)^{2-(\mu /(1-\mu))},
$$

where $k$ is the influence coefficient of group borehole initiation related to the number of the cutting holes and the distribution of the borehole $s ; r_{c}$ is the radius of the crushing zone; $r_{f}$ is the radius of the fractured zone; $\mu$ is Poisson's ratio.

In the presplitting and the smooth blasting, the structure of discontinuous charge is applied to reduce the blasting vibration. Taking discontinuous charge into consideration, the ratio of axial charge is assumed as $\alpha$, and (A.3) could be deduced based on the ideal gas equation.

$$
P_{0}=K\left(\frac{\rho D^{2}}{2(\gamma+1)}\right)^{\nu / \gamma} P_{k}^{(\gamma-\gamma) / \gamma}\left(\frac{a}{b}\right)^{2 \nu}(\alpha)^{\nu} .
$$

The presplitting and smooth blasting boreholes are noncutting hole, and the blasting load acting on the borehole wall could be equivalently applied on the plane determined by the borehole center connection line and the borehole axis. The blasting load can be written as

$$
P_{\mathrm{be}}=k P_{0} \frac{b}{S}
$$

where $S$ is the center distance of the boreholes.

\section{Conflicts of Interest}

No potential conflicts of interest were reported by the authors.

\section{Acknowledgments}

This work is supported by China Postdoctoral Science Foundation (2017M621869) and the Fundamental Research Funds for the Central Universities (2015XKZD05).

\section{References}

[1] D. Ainalis, O. Kaufmann, J.-P. Tshibangu, O. Verlinden, and G. Kouroussis, "Modelling the Source of Blasting for the Numerical Simulation of Blast-Induced Ground Vibrations: A Review," Rock Mechanics and Rock Engineering, vol. 50, no. 1, pp. 1-23, 2016.

[2] C. H. Dowding, Blast Vibration Monitoring and Control, Prentice-Hall, 1985.

[3] C. H. Dowding, "Blast Vibration Monitoring and Control," Rock \& Soil Mechanics, 1987.

[4] C. H. Dowding and C. T. Aimone, "Multiple blast-hole stresses and measured fragmentation," Rock Mechanics and Rock Engineering, vol. 18, no. 1, pp. 17-36, 1985.

[5] A. T. Edwards and T. D. Northwood, "Experimental Studies of the effects of Blasting on structures," Engineer, vol. 210, 1960.

[6] W.-B. Lu, Y. Luo, M. Chen, and D.-Q. Shu, "An introduction to Chinese safety regulations for blasting vibration," Environmental Earth Sciences, vol. 67, no. 7, pp. 1951-1959, 2012.

[7] J. C. Li, H. B. Li, G. W. Ma, and Y. X. Zhou, "Assessment of underground tunnel stability to adjacent tunnel explosion," Tunnelling and Underground Space Technology, vol. 35, pp. 227234, 2013.

[8] N. Jiang and C. Zhou, "Blasting vibration safety criterion for a tunnel liner structure," Tunnelling \& Underground Space Technology Incorporating Trenchless Technology Research, vol. 32, no. 1, pp. 52-57, 2012.

[9] J. S. Lee, S. K. Ahn, and M. Sagong, "Attenuation of blast vibration in tunneling using a pre-cut discontinuity," Tunnelling and Underground Space Technology, vol. 52, pp. 30-37, 2016.

[10] M. Mohamadnejad, R. Gholami, and M. Ataei, "Comparison of intelligence science techniques and empirical methods for prediction of blasting vibrations," Tunnelling and Underground Space Technology, vol. 28, no. 1, pp. 238-244, 2012.

[11] M. Monjezi, M. Ghafurikalajahi, and A. Bahrami, "Prediction of blast-induced ground vibration using artificial neural networks," Tunnelling and Underground Space Technology, vol. 26, no. 1, pp. 46-50, 2011.

[12] J. H. Shin, H. G. Moon, and S. E. Chae, "Effect of blast-induced vibration on existing tunnels in soft rocks," Tunnelling \& Underground Space Technology Incorporating Trenchless Technology Research, vol. 26, no. 1, pp. 51-61, 2011.

[13] J. Zhao, J. G. Cai, X. B. Zhao, and H. B. Li, "Dynamic Model of Fracture Normal Behaviour and Application to Prediction of Stress Wave Attenuation Across Fractures," Rock Mechanics \& Rock Engineering, vol. 41, no. 1, pp. 671-693, 2008.

[14] O. Vorobiev, "Generic strength model for dry jointed rock masses," International Journal of Plasticity, vol. 24, no. 12, pp. 2221-2247, 2008.

[15] O. Vorobiev, "Discrete and continuum methods for numerical simulations of non-linear wave propagation in discontinuous media," International Journal for Numerical Methods in Engineering, vol. 83, no. 1, pp. 482-507, 2010.

[16] I. A. Onederra, J. K. Furtney, E. Sellers, and S. Iverson, "Modelling blast induced damage from a fully coupled explosive charge," International Journal of Rock Mechanics and Mining Sciences, vol. 58, pp. 73-84, 2013.

[17] R. Resende, L. Lamas, J. Lemos, and R. Calçada, "Stress wave propagation test and numerical modelling of an underground complex," International Journal of Rock Mechanics and Mining Sciences, vol. 72, pp. 26-36, 2014. 
[18] M. Chen, W. Lu, and C. Yi, "Blasting vibration criterion for a rock-anchored beam in an underground powerhouse," Tunnelling \& Underground Space Technology Incorporating Trenchless Technology Research, vol. 22, no. 1, pp. 69-79, 2007.

[19] A. Minchinton, "On the Influence of Fundamental Detonics on Blasting Practice," in Proceedings of the International Symposium on Rock Fragmentation by Blasting, 2015.

[20] P.-A. Persson, R. Holmberg, and J. Lee, "Rock blasting and explosives engineering," International Journal of Rock Mechanics \& Mining Sciences \& Geomechanics Abstracts, vol. 278A, 1994.

[21] F. Vanbrabant, E. P. Chacón, and L. A. Quinones, "P and S mach waves generated by the detonation of a cylindrical explosive charge - Experiments and simulations," Fragblast, vol. 6, no. 1, pp. 21-35, 2002.

[22] J. Hallquist, LS-DYNA Keyword User's Manual, Version: 970, 2003.

[23] L. X. Xie, W. B. Lu, Q. B. Zhang et al., "Analysis of damage mechanisms and optimization of cut blasting design under high in-situ stresses," Tunnelling \&Underground Space Technology, vol. 66, no. 1, pp. 19-33, 2017.

[24] L. X. Xie, W. B. Lu, Q. B. Zhang et al., "Damage evolution mechanisms of rock in deep tunnels induced by cut blasting," Tunnelling \& Underground Space Technology Incorporating Trenchless Technology Research, vol. 58, no. 1, pp. 257-270, 2016.

[25] V. R. Feldgun, Y. S. Karinski, and D. Z. Yankelevsky, "The effect of an explosion in a tunnel on a neighboring buried structure," Tunnelling and Underground Space Technology, vol. 44, pp. 4255, 2014.

[26] C. D. Inc, AUTODYN Theory Manual 4.3, 2003.

[27] K. Hibbit, Abaqus/Standard Users Manual i-iii, 1995.

[28] J. W. Kury, H. C. Honig, E. L. Lee et al., Metal Acceleration by Chemical Explosive, 1965.

[29] E. L. Lee, H. C. Hornig, and J. W. Kury, "Adiabatic Expansion Of High Explosive Detonation Products," Tech. Rep. UCRL-50422, 1968.

[30] D. P. Blair, "The free surface influence on blast vibration," International Journal of Rock Mechanics \& Mining Sciences, vol. 77, no. 1, pp. 182-191, 2015.

[31] S. H. Cho and K. Kaneko, "Influence of the applied pressure waveform on the dynamic fracture processes in rock," International Journal of Rock Mechanics and Mining Sciences, vol. 41, no. 5, pp. 771-784, 2004.

[32] J. O. Hallquist, LS-Dyna Theory Manual, vol. 53, No. 1, pp. 155-161, 2006.

[33] C. Jommi and A. Pandolfi, Vibrations Induced by Blasting in Rock: A Numerical Approach Associazionegeotecnica It, vol. 20: 77-94, 2008.

[34] H. K. Kutter and C. Fairhurst, "On the fracture process in blasting," International Journal of Rock Mechanics ¿amp; Mining Sciences \& Geomechanics Abstracts, no. 8:181, IN181, 189-188, IN110, 202, 1971.

[35] G. W. Ma and X. M. An, "Numerical simulation of blastinginduced rock fractures," International Journal of Rock Mechanics \& Mining Sciences, vol. 45, no. 1, pp. 966-975, 2008.

[36] J. H. Yang, W. B. Lu, Z. G. Zhao, P. Yan, and M. Chen, "Safety distance for secondary shotcrete subjected to blasting vibration in Jinping-II deep-buried tunnels," Tunnelling and Underground Space Technology, vol. 43, pp. 123-132, 2014.

[37] A. A. Kuzmenko, V. D. Vorobev, I. I. Denisyuk, and A. A. Dauetas, Seismic Effects of Blasting in Rock, 1993.
[38] W. Lu, J. Yang, M. Chen, and C. Zhou, "An equivalent method for blasting vibration simulation," Simulation Modelling Practice \& Theory, vol. 19, no. 1, pp. 2050-2062, 2011. 


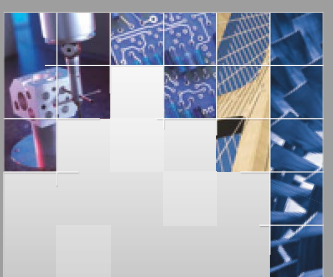

\section{Enfincering}
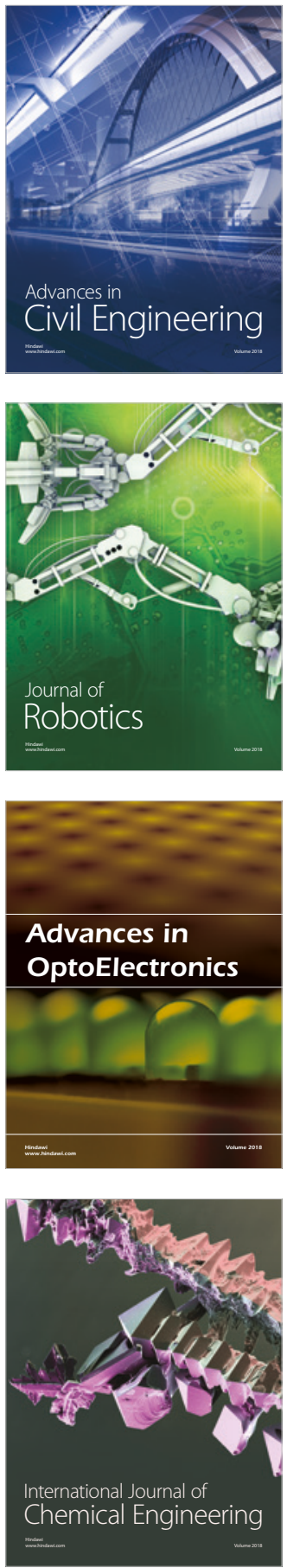

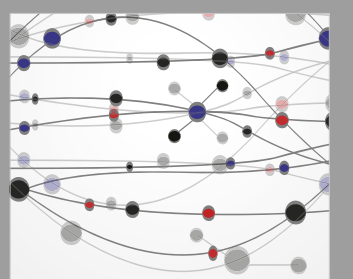

\section{Rotating \\ Machinery}

The Scientific World Journal

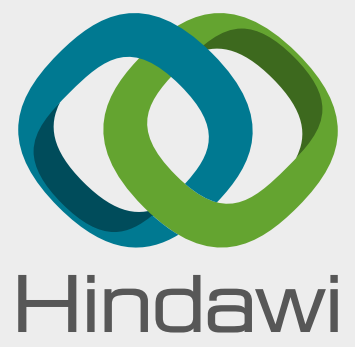

Submit your manuscripts at

www.hindawi.com
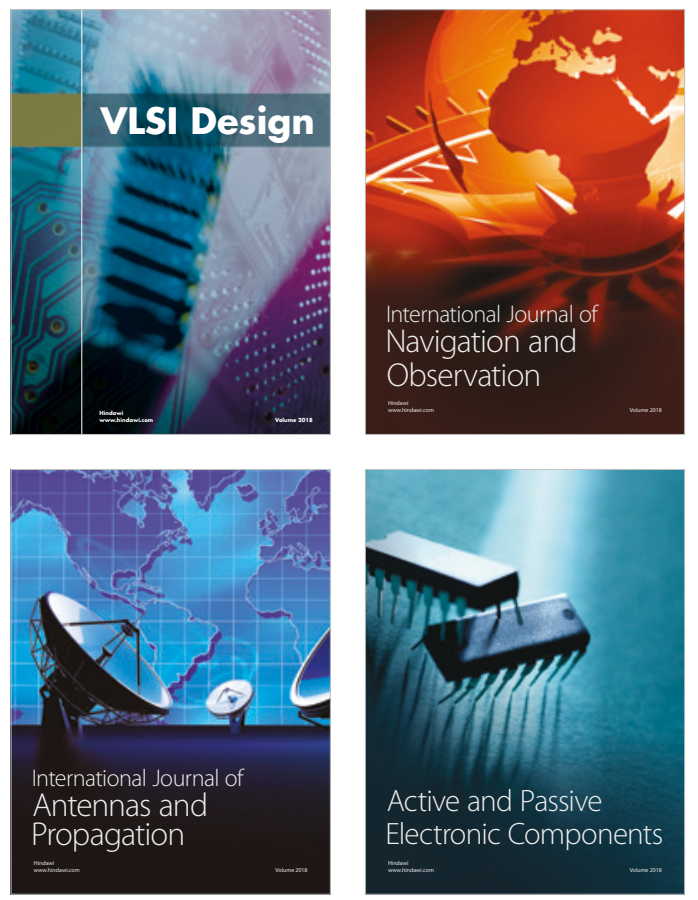
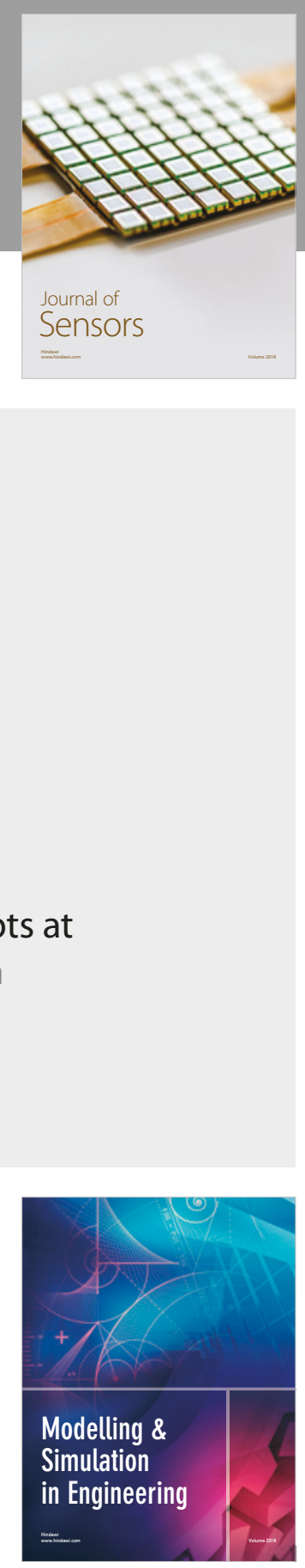

\section{Advances \\ Multimedia}
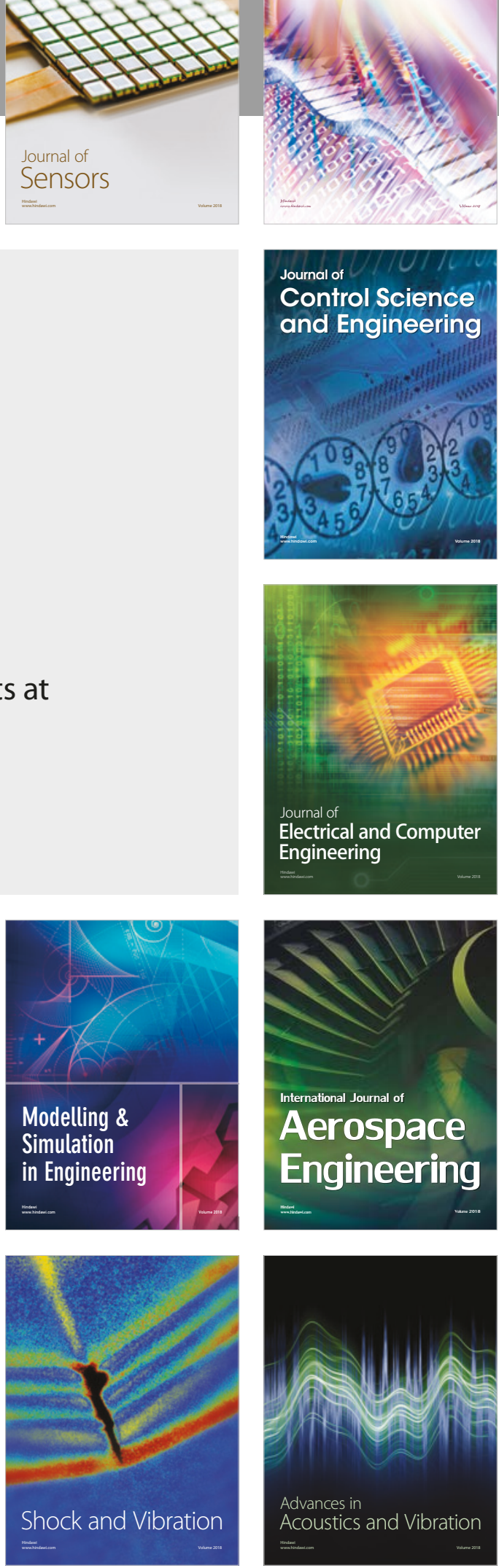